\title{
EFFECTS OF RESVERATROL ON LIVER FUNCTION OF OBESE FEMALE WISTAR RATS
}

\section{EFEITOS DO RESVERATROL NA FUNÇÃO HEPÁTICA DE RATAS WISTAR OBESAS}

\author{
Nádia Araújo Miguel ${ }^{1}$ \\ Silvia Franco Andrade ${ }^{1 *}$ \\ Gisele Nai ${ }^{1}$ \\ Cecília Braga Laposy ${ }^{1}$ \\ Felipe Franco Nascimento ${ }^{1}$ \\ Heloise Rangel Dinallo ${ }^{1}$ \\ Alessandra Melchert ${ }^{2}$ \\ 1 Universidade do Oeste Paulista, Presidente Prudente, SP Brasil \\ ${ }^{2}$ Faculdade de Medicina Veterinária e Zootecnia da Universidade Estadual Paulista, Botucatu, SP, Brasil \\ * Autora para contato - silviafranco@unoeste.br
}

\begin{abstract}
Resveratrol has antioxidant, anti-inflammatory, lipolytic, and antifibrotic properties, which may be useful in supplementation of obese patients and with liver problems. This study evaluated the effects of 6-week resveratrol supplementation on the lipid profile and liver function of female Wistar rats fed a high-fat diet to induce obesity. Sixty-four Wistar rats were divided into 4 groups $(\mathrm{n}=16)$ : the control group $(\mathrm{C})$; the control obese group $(\mathrm{CO})$; the resveratrol group $(\mathrm{R})$; and the resveratrol obese group (RO). At the end of the experiment, the animals were anesthetized for blood collection and subsequent euthanasia for collection of liver biopsy. The parameters for body weight, liver weight, retroperitoneal fat weight, serum lipid and liver profiles and histopathological analysis were evaluated. The 6-week resveratrol administration did not induce weight loss nor did it reduce the lipid profile; however, it decreased the liver enzymes aspartate aminotransferase (AST) and alkaline phosphatase (ALP) and reduced the incidence of steatosis (75.0\%) in group RO compared with group CO (81.2\%). Thus, we concluded that resveratrol supplementation for the short period of six weeks had a beneficial effect on liver function by reducing hepatic steatosis and the liver enzymes AST and ALP in obese female rats.
\end{abstract}

Keywords: liver function; obesity; rats; resveratrol.

\section{Resumo}

O resveratrol possui propriedades antioxidantes, anti-inflamatórias, lipolíticas e antifibróticas que podem ser úteis na suplementação de pacientes obesos e com problemas hepáticos. Este estudo avaliou os efeitos da suplementação de resveratrol durante seis semanas sobre o perfil lipídico e a função hepática de ratas Wistar alimentadas com uma dieta rica em gordura para induzir a obesidade. Sessenta e quatro ratas Wistar foram divididos em 4 grupos $(n=16)$ : grupo controle $(C)$; grupo controle obeso (CO); grupo resveratrol (R); e grupo resveratrol obeso (RO). Ao fim do experimento, os animais foram anestesiados para a coleta de sangue e subsequente eutanásia para coleta de biopsia hepática. Foram avaliados os parâmetros de peso corporal, peso do fígado, peso da gordura retroperitoneal, lipídeos séricos e perfil e análise histopatológica do fígado. A administração de resveratrol por seis semanas não induziu perda de peso nem reduziu o perfil lipídico; no entanto, diminuiu as enzimas hepáticas 
aspartato aminotransferase (AST) e fosfatase alcalina (FA) e reduziu a incidência de esteatose $(75,0 \%)$ em comparação com o grupo RO grupo CO $(81,2 \%)$. Assim, conclui-se que a suplementação de resveratrol para o curto período de seis semanas tiveram um efeito benéfico sobre a função do fígado através da redução esteatose hepática e das enzimas do fígado AST e ALP em ratas obesas.

Palavras-chave: função hepática; obesidade; ratos; resveratrol.

Received on: Nov. $27^{\text {th }}, 2014$

Accepted on: Jan. $21^{\text {st }}, 2016$

\section{Introduction}

Obesity is characterized by body fat excess, primarily due to an imbalance between excessive caloric intake and low energy expenditure associated with poor dietary habits and inadequate physical exercise. The prevalence of obesity (body mass index over $30 \mathrm{~kg} / \mathrm{m}^{2}$ ) has increased dramatically worldwide over the past two decades. In 2009-2010, among the U.S. adult population, 35.5\% of men and $35.8 \%$ of women were obese ${ }^{(1)}$. Overweight and obesity are considered important public health problems, and they are increasing around the world for all age groups, affecting not only adults but also many children and adolescents. In companion animals, such as dogs and cats, its incidence has surpassed $20 \%$ in most industrialized countries ${ }^{(2)}$.

Obesity has negative effects on quality of life and is associated with several comorbidities, such as diabetes mellitus, cerebrovascular stroke, and arterial hypertension ${ }^{(3)}$. Obesity is a chronic and progressive disease that predisposes individuals to an increased mortality rate, as demonstrated in several population studies. Its importance becomes even greater when one notes that its prevalence has increased dramatically, both in developed and developing countries, such as Brazil( ${ }^{(4)}$. It is a multifactorial disease that has multiple cultural, environmental, socioeconomic, psychological, and genetic components ${ }^{(5)}$.

Disorders typical of obese individuals are called metabolic syndromes and include the following: insulin resistance; increased plasma insulin levels; central obesity; changes in total cholesterol and cholesterol fractions, with high levels of low-density lipoproteins (LDL) and low levels of highdensity lipoproteins (HDL); elevated triglyceride levels; and hypertension, among others ${ }^{(6)}$. The main risk attributed to obesity/metabolic syndromes is its associated cardiovascular implications due to its relationship with other risk factors, such as hypertension, insulin resistance and dyslipidemia ${ }^{(7,8)}$.

Nonalcoholic fatty liver disease has been identified as another characteristic associated with metabolic syndrome. It encompasses an increase in free fatty acids concomitant with a decrease in betaoxidation, promoting an increased susceptibility to hepatic fibrosis ${ }^{(9,10)}$. Hepatic fibrosis is a woundhealing response to chronic liver injury, which culminates in cirrhosis and severe liver damage. In hepatic fibrosis, quiescent hepatic stellate cells (HSC) are activated, proliferate, and begin to express an activated myofibroblastic phenotype, losing lipid droplets and vitamin A, and increasing their secretion of extracellular matrix ${ }^{(10,11)}$. Therapeutic agents that block the activation of hepatic stellate cells, i.e., decreasing proliferation and maintaining a lipocytic phenotype, constitute one form of the treatments for fibrosis ${ }^{(12)}$.

The increasing concern regarding food and its constituents incentivizes investments into industries that produce healthy products and the so-called functional foods and supplements. Polyphenols such as resveratrol are among the substances present in various plants, particularly in grapes and its derivatives ${ }^{(12,13)}$. Resveratrol (trans-3, 5, 4'-trihydroxystilbene) is a natural phytoalexin found in grapes and its derivatives, such as red wines, which have been reported to exhibit a wide variety of pharmacological properties. It has antioxidant and anti-inflammatory properties and can modulate lipid metabolism by attenuating hepatic lipid peroxidation, in addition to acting to prevent cancer and cardiovascular diseases and cancer ${ }^{(13-15)}$. 
The effects of resveratrol on lipolysis have been reported, in which the authors observed an enhanced lipolytic response to the adrenaline induced by resveratrol, suggesting that this result is due to an increase in $\mathrm{cAMP}$ in adipocytes ${ }^{(16)}$. A reduction in inflammation via the inhibition of prostaglandins mediated by inhibition of cyclooxygenase- 2 and the nuclear factor-kB (NF-kB) activity has also been reported ${ }^{(17)}$. Inflammatory mediators can stimulate the activation of hepatic stellate cells (HSC) ${ }^{(18)}$. Thus, the anti-inflammatory effect of resveratrol may contribute to the antifibrotic activity observed in liver injury by inhibiting the activation of stellate cells. Recently, resveratrol has been proposed as a substance that has anti-obesity potential due to an effect on energy restriction, leading to a reduction in body fat and an increase in insulin sensitivity ${ }^{(19,20)}$.

Therefore, due to the antioxidant, anti-inflammatory, lipolytic, and antifibrotic properties of resveratrol, which may be useful in supplementation of obese patients and with liver problems, a fact increasingly growing in humans, dogs and cats, the objective of this study was to evaluate the effects of the use of resveratrol on the liver function in diet-induced obese Wistar rats.

\section{Materials and Methods}

The Ethics Committee on Animal Use of the University of Oeste Paulista (Universidade do Oeste Paulista) approved this study, under the protocol N.1195. In total, 64 8-week-old adult female Wistar rats, weighing between 200 and $250 \mathrm{~g}$, were select from the Central Bioterium of UNOESTE and kept in polypropylene cages with 4 animals per cage. The animals were provided food and water ad libitum, and maintained under a 12-hour light/dark photoperiod at a mean temperature of $22{ }^{\circ} \mathrm{C} \pm 2{ }^{\circ} \mathrm{C}$ for 12 weeks. The animals were euthanized at the end of the experiment.

The animals were fed specific diets over the 12-week experiment. During the first six weeks of the experiment, the rats were divided into two groups $(n=32)$ that received two different diets: commercial rat chow (LABINA®; control group) or a palatable high-fat diet (PHFD; obese group). During the final six weeks, they were divided into four groups $(\mathrm{n}=16)$, according to the diet and supplementation provided: control group (C): animals were provided commercial Labina ${ }^{\circledR}$ (Purina, SP, Brazil $)$ chow ad libitum, supplemented daily with a placebo $(0.5 \mathrm{ml}$ of filtered water $)$ via a single oral gavage; resveratrol group (R): animals were provided commercial Labina ${ }^{\circledR}$ (Purina, SP, Brazil) ad libitum, supplemented daily with resveratrol (Fragon do Brazil Farmacêutica, SP, Brazil) at a dose of $30 \mathrm{mg} / \mathrm{kg}$ /day diluted into $0.5 \mathrm{ml}$ of filtered water ${ }^{(21-23)}$ via a single oral gavage, always at the same period of the day; control obese group (CO): animals were provided a palatable high-fat diet (PHFD), supplemented daily with a placebo $(0.5 \mathrm{ml}$ of filtered water $)$ via a single oral gavage; and resveratrol obese group (RO): animals were provided a PHFD supplemented daily with resveratrol, similar to group R.

The PHFD used here was developed by Estadella ${ }^{(24)}$ and consists of a high-calorie, normal-protein, and high-fat mixture containing commercial LABINA ${ }^{\circledR}$ chow, roasted peanuts, milk chocolate, and wafer cornstarch at a ratio of 3:2:2:1, respectively. This diet had the following composition: $20 \%$ protein; 24\% fat; $41 \%$ carbohydrate; $5.9 \%$ fiber; and 5\% mineral residues, and a caloric density of $20.2 \mathrm{~kJ} / 100 \mathrm{~g}$, in which $35 \%$ of calories came from fat, as evaluated using an adiabatic calorimeter ${ }^{(25)}$.

During the final six weeks of the study (the period with resveratrol supplementation), the body weight of rats was measured in grams (g) using a digital scale (ELC-10). At the end of the 12-week study, the animals were anesthetized intraperitoneally with sodium thiopental (Thiopentax ${ }^{\circledR}$ ) at a dose of $60 \mathrm{mg} / \mathrm{kg}$, followed by an intramuscular administration of tiletamine and zolazepam (Zoletil ${ }^{\circledR}$ ) at a dose of $30 \mathrm{mg} / \mathrm{kg}$. Blood was then collected by cardiac puncture for biochemical evaluations. Blood was collected into vacuum tubes without anticoagulant and then centrifuged at $3000 \mathrm{rpm}$ for 15 minutes to obtain serum. Euthanasia was performed via exsanguination by cardiac puncture at the time of the blood collection. Vital parameters such as the absence of reflexes, respiratory movements 
and electrocardiographic records using computerized electrocardiogram (PC ECG, TEB ${ }^{\circledR}$ ) that are compatible with life were verified to confirm animal death. Following euthanasia, the liver and retroperitoneal fat were collected and measured in grams on precision digital scales (Marte $\mathrm{A} 500^{\circledR}$ )

To determine the lipid profile, triglycerides, total cholesterol, and HDL cholesterol (high-density lipoproteins) were evaluated, and for the liver profile, the enzymatic levels of alkaline phosphatase (ALP), aspartate aminotransferase (AST), and alanine aminotransferase (ALT) were measured. Cholesterol and triglyceride tests were performed using an enzymatic colorimetric method in a kit $\left(\right.$ Labtest $\left.^{\circledR}\right)$. The HDL cholesterol, ALP, AST, and ALT tests were performed using the kinetic method, also using a kit $\left(\right.$ Labtest $\left.^{\mathbb{}}\right)$. All tests were measured in a semi-automatic analyzer (Quick Lab II Drake $^{\circledR}$ ) in the Clinical Pathology Laboratory at the Veterinary Hospital of Unoeste.

Liver samples were collected for histopathological analysis. The liver fragments were fixed in $10 \%$ formalin for 24 hours and processed using standard histological procedures including paraffin embedding. Five-micron sections were generated and stained with hematoxylin-eosin (HE). All procedures were performed at the Anatomic Pathology Laboratory, Unoeste. Histological sections of liver were analyzed under a Labophot microscope $\left(\mathrm{Nikon}^{\circledR}\right)$ at 100X magnification and classified based on the presence of congestion, inflammatory infiltration, cholestasis, steatosis, and hepatic necrosis.

The data were tested for normality using the Shapiro-Wilk test. Analysis of variance was used to compare the means and standard deviations of the body weights of the groups at each time point, and differences were further analyzed using the Tukey method. For comparisons between time points within each group, repeated measures analysis of variance was used, and differences were compared using the Sidak method. The assumption of data sphericity was validated using Mauchly's test of sphericity. For the lipid and hepatic profile and organ weight data, analysis of variance was used to compare the means and standard deviations between the different groups, and differences were confirmed using the Tukey method. The level of significance was set at 5\%. For liver histopathology, descriptive analyses were performed.

\section{Results}

In the weekly evolution of each group, the $\mathrm{CO}$ group showed a significant increase in body weight beginning at week 5 of the study, and the RO group showed an increase in body weight as early as week 2 of supplementation. Groups $C$ and $R$ showed no significant weight gain $(p>0.05)$ over the 6 -week study. Upon comparing the groups, the animals in the RO group weighed more than the animals in groups $\mathrm{C}$ and $\mathrm{R}$ from week 2 to week 6 and more than the animals in the $\mathrm{CO}$ group from week 2 to week 4 of the study. The CO group only had significantly heavier weight $(\mathrm{p}<0.05)$ than groups $\mathrm{C}$ and $\mathrm{R}$ in the final weeks of the study (weeks 5 and 6). There were no significant differences $(\mathrm{p}>0.05)$ in the weights between groups $\mathrm{R}$ and $\mathrm{C}$ (Table 1). Regarding liver and retroperitoneal fat weights (Table 2$)$, the RO group only had significantly more fat weight $(\mathrm{p}<0.05)$ than the other groups in the final weeks of the study.

There were no significant differences $(\mathrm{p}>0.05)$ in the mean values for cholesterol, HDL cholesterol, and triglycerides between groups $\mathrm{C}, \mathrm{CO}, \mathrm{R}$, and RO (Table 3 ). There was a significant difference $(p<0.05)$ in ALT values of the RO group, whose values were significantly higher than those observed in groups $\mathrm{C}, \mathrm{CO}$, and R. The values for the AST and ALP parameters were significantly lower $(\mathrm{p}<0.05)$ for groups $\mathrm{R}$ and $\mathrm{RO}$ compared with groups $\mathrm{C}$ and $\mathrm{CO}$. Significantly higher ALP values were observed in the CO group compared with other groups. Group $\mathrm{C}$ showed a significant increase $(\mathrm{p}<0.05)$ compared with groups $\mathrm{R}$ and $\mathrm{RO}$ but a decrease compared with the CO group (Table 4). The total cholesterol, HDL cholesterol, triglycerides, ALT, AST, and ALP values were within the normal reference values for the species (Tables 3 and 4). 
Table 1. Means and standard deviations for the body weight, in grams, of the Wistar rats in the control, control obese, resveratrol, and resveratrol obese groups during the 6 -week study

\begin{tabular}{ccccc}
\hline \multirow{2}{*}{ Week } & \multicolumn{4}{c}{ Weight $(\mathbf{g}) /$ Groups } \\
\cline { 2 - 5 } & Control & $\begin{array}{c}\text { Control } \\
\text { Obese }\end{array}$ & Resveratrol & $\begin{array}{c}\text { Resveratrol } \\
\text { Obese }\end{array}$ \\
\hline 1 & $221.3 \pm 17.8(\mathrm{Aa})^{*}$ & $212.1 \pm 19.3(\mathrm{Aa})$ & $207.5 \pm 14.5(\mathrm{Aa})$ & $221.2 \pm 17.8(\mathrm{Aa})$ \\
2 & $209.0 \pm 13.5(\mathrm{Aa})$ & $222.2 \pm 18.7(\mathrm{Aa})$ & $210.9 \pm 15.1(\mathrm{Aa})$ & $234.7 \pm 18.4(\mathrm{Bb})$ \\
3 & $210.2 \pm 16.2(\mathrm{Aa})$ & $225.7 \pm 20.3(\mathrm{Aa})$ & $215.6 \pm 16.5(\mathrm{Aa})$ & $239.9 \pm 22.8(\mathrm{Bb})$ \\
4 & $214.0 \pm 15.8(\mathrm{Aa})$ & $223.1 \pm 29.2(\mathrm{Aa})$ & $222.3 \pm 16.3(\mathrm{Aa})$ & $251.3 \pm 25.7(\mathrm{Bb})$ \\
5 & $216.4 \pm 16.3(\mathrm{Aa})$ & $237.6 \pm 20.8(\mathrm{Bb})$ & $227.1 \pm 13.5(\mathrm{Aa})$ & $257.3 \pm 24.2(\mathrm{Bb})$ \\
6 & $224.3 \pm 15.8(\mathrm{Aa})$ & $242.7 \pm 22.5(\mathrm{Bb})$ & $226.5 \pm 16.6(\mathrm{Aa})$ & $262.1 \pm 20.8(\mathrm{Bb})$ \\
\hline
\end{tabular}

*Uppercase letters represent a comparison of groups for each time point and lowercase letters represent a comparison of time points within each group. Different letters indicate significant differences $(p<0.05)$.

Table 2. Means and standard deviations for the liver and retroperitoneal fat weights, in grams, of the Wistar rats in the control, control obese, resveratrol and resveratrol obese groups during the 6-week study

\begin{tabular}{ccc}
\hline Groups & Liver weight (g) & Retroperitoneal Fat (g) \\
\hline Control & $6.6 \pm 0.5(\mathrm{~A})$ ** & $2.5 \pm 1.0(\mathrm{~A})$ \\
Control obese & $7.5 \pm 1.1(\mathrm{~A})$ & $3.3 \pm 1.5(\mathrm{~A})$ \\
Resveratrol & $6.7 \pm 0.7(\mathrm{~A})$ & $2.3 \pm 0.9(\mathrm{~A})$ \\
Resveratrol obese & $8.3 \pm 1.2(\mathrm{~B})$ & $4.4 \pm 1.7(\mathrm{~B})$ \\
\hline *Uppercase letters compare between groups. Different letters indicate significant differences $(\mathrm{p}<0.05)$.
\end{tabular}

Table 3. Means and standard deviations of cholesterol, triglycerides, HDL cholesterol serum values in $\mathrm{mg} / \mathrm{dL}$ of the Wistar rats in the control, control obese, resveratrol, and resveratrol obese groups

\begin{tabular}{cccc}
\hline & \multicolumn{3}{c}{ Values (mg/dL) } \\
\cline { 2 - 4 } Groups & Cholesterol & HDL cholesterol & Triglycerides \\
\hline Control & $54.3 \pm 12.1(\mathrm{~A})^{*}$ & $50.8 \pm 11.1(\mathrm{~A})$ & $71.0 \pm 22.9(\mathrm{~A})$ \\
Control obese & $63.5 \pm 14.3(\mathrm{~A})$ & $50.1 \pm 12.5(\mathrm{~A})$ & $79.1 \pm 22.6(\mathrm{~A})$ \\
Resveratrol & $69.8 \pm 15.8(\mathrm{~A})$ & $52.0 \pm 9.0(\mathrm{~A})$ & $68.3 \pm 21.1(\mathrm{~A})$ \\
Resveratrol obese & $64.1 \pm 16.7(\mathrm{~A})$ & $52.3 \pm 9.6(\mathrm{~A})$ & $79.6 \pm 21.6(\mathrm{~A})$ \\
\hline
\end{tabular}

Reference values: Cholesterol, $24-73 \mathrm{mg} / \mathrm{dL}$; triglycerides, $20-114 \mathrm{mg} / \mathrm{dL}$; HDL cholesterol, $48.0 \pm 11.4 \mathrm{mg} / \mathrm{dL}$.(30)

*Uppercase letters represent a comparison between groups. Different letters indicate significant differences $(\mathrm{p}<0.05)$.

Table 4. Means and standard deviations of serum liver enzymes in $\mathrm{U} / \mathrm{L}$ for aspartate aminotransferase (AST), alanine aminotransferase (ALT), and alkaline phosphatase (ALP) of the Wistar rats in the control, control obese, resveratrol, and resveratrol obese groups

\begin{tabular}{cccc}
\hline & \multicolumn{3}{c}{ Values $(\mathbf{m g} / \mathbf{d L})$} \\
\cline { 2 - 4 } Groups & ALT & AST & ALP \\
\hline Control & $29.9 \pm 7.9(\mathrm{~A})^{*}$ & $136.3 \pm 42.9(\mathrm{~A})$ & $139.1 \pm 84.5(\mathrm{~A})$ \\
Control obese & $31.7 \pm 7.2(\mathrm{~A})$ & $138.5 \pm 60.0(\mathrm{~A})$ & $186.4 \pm 55.5(\mathrm{~B})$ \\
Resveratrol & $29.4 \pm 10.7(\mathrm{~A})$ & $115.2 \pm 45.9(\mathrm{C})$ & $118.2 \pm 56.6(\mathrm{C})$ \\
Resveratrol obese & $41.9 \pm 10.3(\mathrm{~B})$ & $110.8 \pm 53.4(\mathrm{C})$ & $119.3 \pm 31.9(\mathrm{C})$ \\
\hline
\end{tabular}

Reference Values: ALT, 16 - $48 \mathrm{U} / \mathrm{L}$; AST, 65 - $203 \mathrm{U} / \mathrm{L}$; ALP, 26 - $147 \mathrm{U} / \mathrm{L} .^{17}$

*Uppercase letters represent a comparison between groups. Different letters indicate significant differences $(p<0.05)$.

The histopathological findings revealed no lesions in the liver parenchyma and an absence of cholestasis and necrosis in group C (Figure 1 - A1, A2, and A3) and an absence of hepatic necrosis in groups $\mathrm{CO}, \mathrm{R}$, and $\mathrm{RO}$. Group $\mathrm{R}$ showed $87.5 \%$ mild congestion and $12.5 \%$ moderate congestion, and $87.5 \%$ of these rats showed no inflammatory infiltrate in the liver parenchyma. In contrast, $8 \%$ of the rats in this group showed inflammatory infiltrate with presence of lymphocytes in the portal space (Figure $1-\mathrm{B} 1$ and B2) and 4.5\% showed neutrophils, without steatosis. In the groups provided the high-fat diet, we observed the presence of hepatic steatosis, and $18.75 \%$ of the rats in the CO group showed moderate congestion without inflammatory infiltrate and $81.25 \%$ of the rats showed diffuse microvesicular steatosis (Figure $1-\mathrm{C} 1$ and $\mathrm{C} 2$ ). On the other hand, the RO group showed mild 
congestion without inflammatory infiltrate, but $75 \%$ of rats showed diffuse microvesicular steatosis and focal macrovesicular steatosis (Figure 1-D1 and D2).

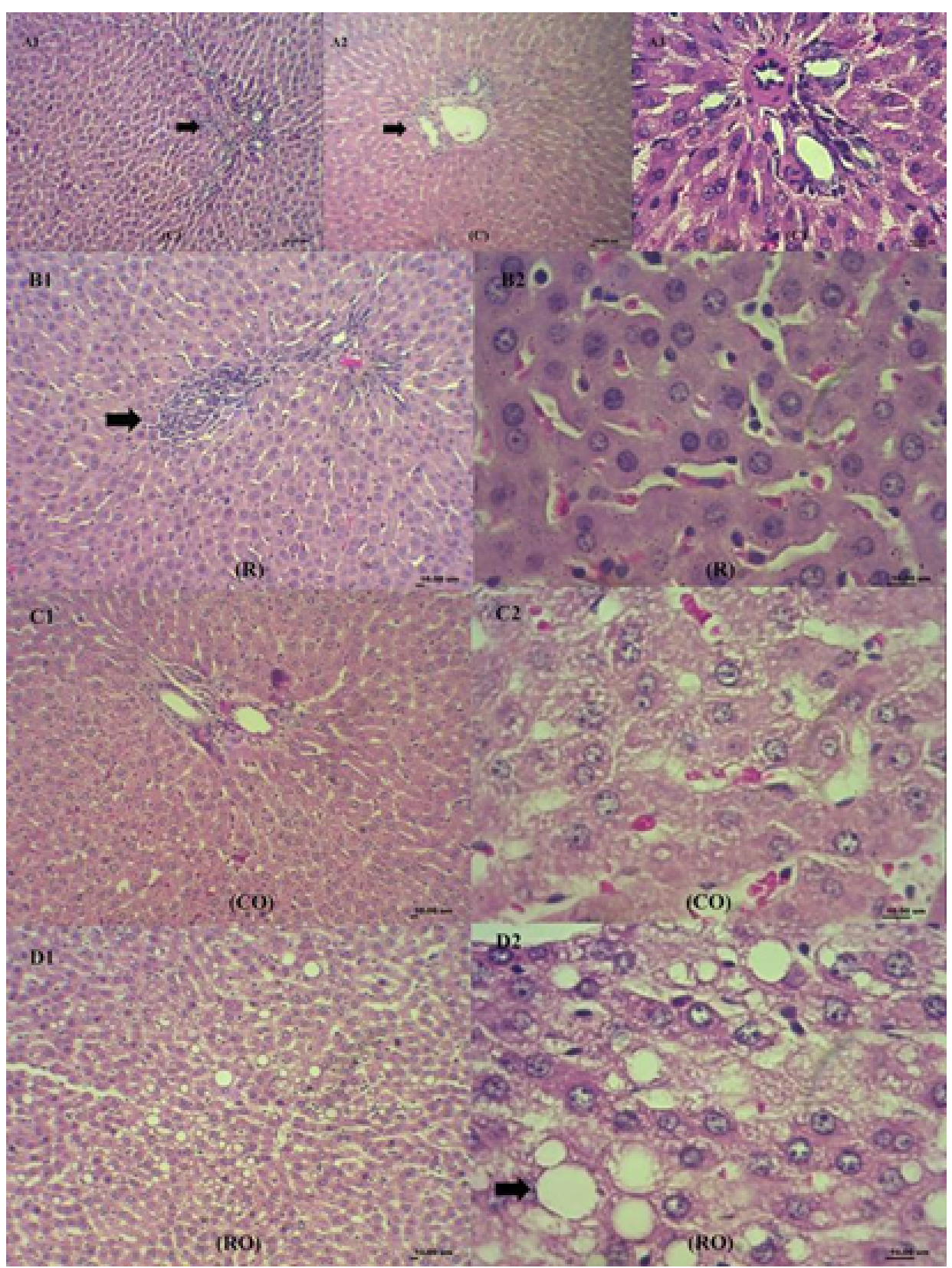

Figure 1. Control group (C) - Histological section of a normal liver - rats n.1 A1 and n.5 A.2 - portal space (arrow) and hepatocyte cords (hematoxylin-eosin, 100x magnification). A3 - Increased magnification of the portal space (hematoxylin-eosin, 400x magnification). Resveratrol group (R) - B1 - Histological section of a rat liver (n.2) with focal mononuclear infiltrate between hepatocytes (arrow; hematoxylin-eosin, 100x magnification). B2 - Increased magnification of normal rat hepatocytes n. 4 (hematoxylin-eosin, 400x magnification). Control obese (CO) $\mathrm{C} 1$ - Histological section of rat liver n.6 with steatosis (hematoxylineosin, 100x magnification). $\mathrm{C} 2$ - Increased magnification showing diffuse microvesicular steatosis in rat $\mathrm{n} .1$ (hematoxylin-eosin, 400x magnification). Resveratrol obese (RO) D1- Histological liver section of rat $\mathrm{n}$. 14 with steatosis (hematoxylin-eosin, 100x magnification). D2 - Increased magnification showing diffuse microvesicular steatosis in rat $\mathrm{n} .15$ and foci of macrovesicular steatosis (arrow) (hematoxylin-eosin, 400x magnification) rat $n .8$. 


\section{Discussion}

During the six weeks of supplementation (resveratrol or placebo) in the present study, the thin groups (C and $\mathrm{R}$ ) did not gain weight; however, the obese groups ( $\mathrm{CO}$ and $\mathrm{RO}$ ) did exhibit significant weight gain. The administration of resveratrol (RO) did not prevent weight gain; instead, the weight gain in the RO group was greater than that observed in the $\mathrm{CO}$ group. The liver and retroperitoneal fat weights were significantly higher in the RO group. These results differ from published studies ${ }^{(21)}$ that have reported a reduction in body fat in rats fed a high-fat diet and supplemented with resveratrol. These effects were attributed to a reduction in lipogenesis, and the positive effects of resveratrol on lipolysis due to an increase in the enzyme hormone-sensitive lipase (HSL), indicating that this polyphenol molecule acts on different forms of lipases and increases the lipolytic response to the epinephrine induced by resveratrol. These effects are the result of an increase in cyclic AMP in adipocytes ${ }^{(16)}$. In contrast to these reports, resveratrol was unable to prevent weight gain in the present study. However, one must consider that the rats were fed a PHFD with $35 \%$ of calories being derived from lipids, whereas in the reports mentioned above, the concentration of lipids in the PHFD was only $22.5 \%{ }^{(21,25)}$.

In the lipid profile, there were no changes in serum cholesterol, HDL cholesterol and triglyceride concentrations in all experimental groups, inconsistent with previous studies ${ }^{(26)}$ in which the authors investigated the lipid-lowering effect of resveratrol, mediated via a decrease in HMG-CoA reductase (hydroxy-3 methyl glutaryl CoA reductase) mRNA expression. HMG-CoA reductase is one of the enzymes involved in the synthesis of cholesterol (LDL cholesterol) and other isoprenoids via the mevalonate metabolic pathway. These authors also reported that resveratrol increased the ratio of the apolipoproteins Apo A1 and Apo B, the primary protein component of plasma HDL cholesterol. These reports were obtained following eight weeks of treatment with resveratrol, whereas supplementation in the present study lasted six weeks. For hepatic function, the levels of the enzyme ALT were higher in the RO group, which can be interpreted as an evolution of liver steatosis to steatohepatitis ${ }^{(27)}$. In addition, data published in the "Third National Health and Nutrition Survey" indicated that there is a significant association between high ALT levels, insulin resistance, type-2 diabetes mellitus, and metabolic syndrome ${ }^{(28)}$. In the present study, AST and ALP levels were significantly lower in groups $\mathrm{R}$ and RO. The literature indicates that abnormalities in serum AST and ALP levels only occur in severe cases of advanced nonalcoholic fatty liver disease, which may suggest that resveratrol has a protective effect in the evolution of hepatic steatosis ${ }^{(9)}$.

The histopathological findings showed that the administration of resveratrol to the rats in the control group induced mild to moderate hepatic congestion, which suggests that the resveratrol treatments reduced the expression of interleukin 6 (IL-6) and the activity of the nuclear factor NF - $\mathrm{kB}$ and COX enzyme ${ }^{(5)}$, which together are key mediators of the inflammatory response ${ }^{(29)}$. In the groups that received the high-calorie diet $(\mathrm{CO}, \mathrm{RO})$, hepatic steatosis was observed in all the animals, which can be explained by the fact that visceral fat is drained directly into the portal system, exposing the liver to large quantities of free fatty acids, thus increasing the hepatic synthesis of triglycerides, while also reducing the liver's ability to secrete them, resulting in the accumulation in hepatocytes ${ }^{(26-29)}$. The administration of resveratrol in the present study decreased the percentage of steatosis from $81.25 \%$ (CO) to $75 \%$ (RO), likely by preventing triglyceride accumulation in hepatocytes by inhibiting the transcription factor SREBP1 via an increase in sirtuin 1, suggesting that the use of resveratrol may have a possible benefit in the treatment of nonalcoholic fatty liver disease (steatosis) ${ }^{(18)}$.

We concluded that resveratrol supplementation, even over a short, 6-week treatment period, had a positive effect on liver function, decreasing the liver enzymes AST and ALP and the occurrence of hepatic steatosis. However, it increased the serum concentrations of ALT in obese female rats and did not affect body weight loss or the lipid profile. Further studies should be conducted including the addition of physical exercise to further elucidate the effects of resveratrol in lean and obese patients over a short treatment period. 


\section{Acknowledgments}

The authors thank the graduate program of UNOESTE for financial support.

\section{References}

1. Flegal KM, Carroll MD, Kit BK, Ogden CL. Prevalence of obesity and trends in the distribution of body mass index among US adults 1999-2010. Journal of Vascular Nursing. 2013;31(3):131-132.

2. Raffan E. The big problem: battling companion animal obesity. Veterinary Record. 2013;173(12):287-91

3. James P, Rigby N, Leach R, Force IOT. The obesity epidemic, metabolic syndrome and future prevention strategies. European Journal of Cardiovascular Prevention and Rehabilitation. 2004;11(1):3-8.

4. Conde WL, Monteiro CA. Nutrition transition and double burden of undernutrition and excess of weight in Brazil. Journal of Clinic Nutrition. 2014;100(6):1617S-22S.

5. Anderson JW, Konz EC. 2001. Obesity and disease management: effects of weight loss on comorbid conditions. Obesity Research. Suppl 4:326S-334S..

6. Defronzo RA, Ferrannini E. Insulin resistance. A multifaceted syndrome responsible for NIDDM, obesity, hypertension, dyslipidemia and atherosclerotic cardiovascular disease. Diabetes Care. 1991;14(3):173-194.

7. Zoran DL. Obesity in dogs and cats: a metabolic and endocrine disorder. Veterinary clinics of North America Small Animal Practice. 2010;40(2):221-39.

8. Carneiro G, Faria NA, Ribeiro Filho FF. Influence of body fat distribution on the prevalence of arterial hypertension and other cardiovascular risk factors in obese patients. Revista da Associação de Médica Brasileira. 2003;49(3):306-311.

9. Marchesini G, Brizi M, Bianchi G, Tomassetti S, Bugianesi E, Lenzi M, Mccullough AJ, Natale S, Forlani G, Melchionda N. Nonalcoholic fatty liver disease: a feature of metabolic syndrome. Diabetes. 2001;50(8):18841850.

10. Fisher CP, Kierzek AM, Plant NJ, Moore JB. Systems biology approaches for studying the pathogenesis of non-alcoholic fatty liver disease. World Journal of Gastroenterology. 2014;20(41):15070-15078.

11. Friedman SL. Hepatic stellate cells: protean, multifunctional, and enigmatic cells of the liver. Physiological Reviews. 2008;88(1):125-172.

12. Pan MH, Lail CS, Tsai ML, Ho CT. Chemoprevention of nonalcoholic fatty liver disease by dietary natural compounds. Molecular Nutrition and Food Research. 2014;58(1):147-171.

13. Athar M, Back JH, Tang X, Kim HK, Kopelovich L, Bickers DR, Kim A. Resveratrol: a review of preclinical studies for human cancer prevention. Toxicol Appl Pharmacology. 2007;224(3):274-283.

14. Fremont L. Biological effects of resveratrol. Life Science. 2000;66(8):663-667.

15. Baur JA, Sinclair DA. Therapeutic potential of resveratrol: the in vivo evidence. Nature Reviews Drug Discovery. 2006;5(6):493-506.

16. Szkudelska K, Nogowski L, Szkudelski T. Resveratrol, a naturally occurring diphenolic compound, affects lipogenesis, lipolysis and the antilipolytic action of insulin in isolated rat adipocytes. Journal of Steroid Biochemistry and Molecular Biology. 2009;113(1-2):17-24.

17. Shankar S, Singh G, Srivastava RK. Chemoprevention by resveratrol: molecular mechanisms and therapeutic potential. Frontiers in Bioscience. 2007; 12:4839-4854. 
18. Wallace K, Burt AD, Wright MC. Liver fibrosis. Biochemical Journal. 2008;411(1):1-18.

19. Lagouge M, Argmann C, Gerhart-Hines Z, Meziane H., Lerin C, Daussin F, Messadeq N, Milne J, Lambert P, Elliott P, Geny B, Laakso M, Puigserver P, Auwerx J. Resveratrol improves mitochondrial function and protects against metabolic disease by activating SIRT1 and PGC-1alpha. Cell. 2006;27(6):1109-1122.

20. Baile CA, Yang JY, Rayalam S, Hartzell DL. Effect of resveratrol on fat mobilization. Annals of the New York Academy of Sciences. 2011;1215:40-47.

21. Alberdi G, Rodríguez V, Miranda J, Macarulla M, Arias N, Lacueva A, Portillo M. Changes in white adipose tissue metabolism induced by resveratrol in rats. Nutrition and Metabolism. 2011;8(1):29.

22. Goldberg DMNG, Yan J, Karumanchiri A. Regional differences in resveratrol isomer concentrations of wines from various cultivars. Journal of Wine Research. 1996; 7:13-24.

23. Zamora-Ros R, Andres-Lacueva C, Lamuela-Raventós R, Berenguer T. Concentrations of resveratrol and derivatives in foods and estimation of dietary intake in a Spanish population: European Prospective Investigation into Cancer and Nutrition (EPIC)-Spain cohort. British Journal of Nutrition. 2008;100(1):188-196.

24. Estadella D, Oyama LM, Bueno AA, Habitante CA, Souza GI, Ribeiro EB, Motoyama CSM, do Nascimento CMO. Palatable hyperlipidic diet causes obesity and affects brain glucose metabolism in rats. Lipid Health Disease. 2011;10:1-9.

25. Bueno AA, Habitante CA, Oyama LM, Estadella D, Ribeiro EB, Oller do Nascimento CM. White adipose tissue re-growth after partial lipectomy in high fat diet induced obese Wistar rats. Journal of Physiology Science. 2011;61(1):55-63.

26. Cho LJ, Ahn JY, Kim S. Resveratrol attenuates the expression of HMG-CoA reductase mRNA in hamsters. Biochemical and Biophysical Research Communications. 2008;367(1):190-194.

27. Liangpunsakul S, Chalasani N. Unexplained elevations in alanine aminotransferase in individuals with the metabolic syndrome: results from the Third National Health and Nutrition Survey (NHANES III). American Journal of the Medical Sciences. 2005;329(3):111-116.

28. Gómez ZS, Fernández QA, Lasa A, Hijona E, Bujanda L, Portillo MP. Effects of resveratrol on obesityrelated inflammation markers in adipose tissue of genetically obese rats. Nutrition. 2013; 29(11-12):1374-80.

29. Wang GL, Fu YC, Xu WC. Resveratrol inhibits the expression of SREBP1 in cell model of steatosis via Sirt1-FOXO1 signaling pathway. Biochemical and Biophysical Research Communications. 2009;380(3):644649.

30. Giknis MLA, Clifford CB. 2008. Clinical laboratory parameters for Crl:WI (Han) Rats. Charles Rivers Laboratories. 